\author{
Ecología
}

\title{
Diversidad de Trichoderma en el agroecosistema cacao del estado de Tabasco, México
}

\author{
Trichoderma diversity in the cocoa agroecosystem in the state of Tabasco, Mexico \\ Magdiel Torres-De la Cruz ${ }^{\mathrm{a}}$, Carlos F. Ortiz-García ${ }^{\mathrm{b}}$, Consuelo Bautista-Muñoz ${ }^{\mathrm{a}, \mathrm{b}, \mathrm{c}}$, \\ José Abraham Ramírez-Pool $^{c}$, Nayely Ávalos-Contreras ${ }^{a}$, Silvia Cappello-García ${ }^{a}$ \\ y Aracely De la Cruz-Pérez ${ }^{\text {a,* }}$ \\ ${ }^{a}$ División Académica de Ciencias Biológicas, Universidad Juárez Autónoma de Tabasco. Km. 0.5 Carretera Villahermosa-Cárdenas, 86039 Tabasco, México \\ ${ }^{\mathrm{b}}$ Colegio de Postgraduados, Campus Tabasco. Km. 3.5 Carretera Cárdenas-Huimanguillo, H. Cárdenas, 86500 Tabasco, México \\ ${ }^{\mathrm{c}}$ Departamento de Biotecnología y Bioingeniería, Centro de Investigación y de Estudios Avanzados, Instituto Politécnico Nacional. Av. Instituto Politecnico \\ Nacional 2508, Delegación Gustavo A. Madero, Colonia San Pedro Zacatenco, 07360 México, D.F., México
}

Recibido el 29 de octubre de 2013; aceptado el 8 de julio de 2015

Disponible en Internet el 6 de noviembre de 2015

\begin{abstract}
Resumen
Las plantaciones de cacao de Tabasco tienen similitud con las selvas tropicales. Este agroecosistema ayuda a conservar la biodiversidad. En la entidad, los estudios de diversidad en el agroecosistema cacao están relacionados con la vegetación, mamíferos, avifauna, insectos y arañas. La diversidad de hongos no se ha estudiado. El objetivo del presente trabajo fue caracterizar la diversidad de Hypocrea/Trichoderma presente en la rizósfera de Theobroma cacao en Tabasco, México. Para este fin, se obtuvieron e identificaron 96 aislamientos de Hypocrea/Trichoderma mediante morfología y secuencias de ITS. Las especies encontradas fueron Trichoderma asperellum, T. brevicompactum, T. harzianum/H. lixii, T. koningiopsis/H. koningiopsis, T. longibrachiatum/H. sagamiensis, T. pleuroticola, T. reesei/H. jecorina, T. spirale y T. virens/H. virens. Los índices de riqueza $\left(\mathrm{D}_{\mathrm{Mg}}\right)$ y abundancia $\left(\mathrm{H}^{\prime}\right)$ fueron de 1.75 y 1.69 , respectivamente. El índice de uniformidad de Pielou $(J)$ fue de 0.77 . La mayor diversidad de Trichoderma/Hypocrea se detectó en la subregión Chontalpa. Trichoderma harzianum/H. lixii fue la especie más abundante. Todas las especies encontradas son primer registro para el agroecosistema cacao en Tabasco. Trichoderma asperellum, T. brevicompactum, T. koningiopsis/ H. koningiopsis, T. pleuroticola, T. reesei/H. jecorina y T. spirale son registros nuevos para la entidad y Trichoderma pleuroticola es registro nuevo para México.
\end{abstract}

Derechos Reservados (C) 2015 Universidad Nacional Autónoma de México, Instituto de Biología. Este es un artículo de acceso abierto distribuido bajo los términos de la Licencia Creative Commons CC BY-NC-ND 4.0.

Palabras clave: Biodiversidad; Micromicetos; Rizósfera de cacao

\begin{abstract}
Cocoa plantations of Tabasco are similar to rainforests. This agro-ecosystem contributes to preserve the biodiversity. In Tabasco, diversity studies in the cacao agro-ecosystem are related to the vegetation, mammals, birds, insects and spiders. The fungal diversity has not been studied. The aim of this study was to characterize the diversity of Trichoderma/Hypocrea from the cocoa rhizosphere in cocoa production areas of Tabasco. To this end, 96 strains of Hypocrea/Trichoderma were obtained and identified by morphology and ITS sequences. Trichoderma asperellum, T. brevicompactum, T. harzianum/H. lixii, T. koningiopsis/H. koningiopsis, T. longibrachiatum/H. sagamiensis, T. pleuroticola, T. reesei/H. jecorina, $T$. spirale y $T$. virens $/ H$. virens, were the identified species. The richness $\left(\mathrm{D}_{\mathrm{Mg}}\right)$ and abundance $\left(\mathrm{H}^{\prime}\right)$ indexes were $1.75 \mathrm{y} 1.69$, respectively. The Pielou uniformity index $(J)$ was 0.77 . The highest diversity of Trichoderma/Hypocrea was detected in the Chontalpa subregion. T. harzianum/ H. lixii was the most abundant. All the species are first report for the cocoa agroecosystem of Tabasco. Trichoderma asperellum, T. brevicompactum,
\end{abstract}

\footnotetext{
* Autor para correspondencia.

Correo electrónico: arace_lycp@ hotmail.com (A. De la Cruz-Pérez).

La revisión por pares es responsabilidad de la Universidad Nacional Autónoma de México.
} 
T. koningiopsis/H. koningiopsis, T. pleuroticola, T. reesei/H. jecorina y T. spirale, are new reports for the state. Trichoderma pleuroticola is new record for Mexico.

All Rights Reserved (C) 2015 Universidad Nacional Autónoma de México, Instituto de Biología. This is an open access item distributed under the Creative Commons CC License BY-NC-ND 4.0.

Keywords: Biodiversity; Micromycetes; Cocoa rhizosphere

\section{Introducción}

El estado de Tabasco es productor de cacao con más de 500 años de práctica (Córdova-Ávalos et al., 2001). Sus plantaciones se caracterizan por ser un agroecosistema arbolado de sombra, que forma un paisaje heterogéneo a causa de la diversidad florística asociada a ellos. Debido a las condiciones climáticas donde se cultiva y por establecerse bajo un dosel diversificado de sombra, este agroecosistema tiene similitud con las selvas tropicales (Greenberg, Bichier y Cruz, 2000). Además, éste contribuye considerablemente a conservar la biodiversidad, provee importantes servicios ambientales (Vandermeer, 2003) y aporta una cantidad significativa de materia orgánica que protege el suelo (Rice y Greenberg, 2000; Rivas-Rojas, 2005).

En el agroecosistema cacao del estado de Tabasco, los estudios de diversidad están relacionados con la vegetación, aves e insectos (Córdova-Ávalos et al., 2001; Greenberg et al., 2000; Ibarra, Arriaga y Estrada, 2001; Muñoz, Estrada y Naranjo, 2005; Pérez-De la Cruz et al., 2009; Pérez-De la Cruz, SánchezSoto, Ortiz-García, Zapata-Mata y De la Cruz-Pérez, 2007); sin embargo, la diversidad de hongos ha sido poco estudiada. Las características únicas de este agroecosistema sugieren la existencia de una amplia diversidad de hongos, tales como especies del género Trichoderma, cuyo teleomorfo es Hypocrea (Ascomycota: Hypocreales).

Trichoderma/Hypocrea es un género de hongos cosmopolita y habitante de suelos, madera en descomposición y restos de plantas (Klein y Eveleigh, 1998). Diversas especies de este género están asociadas con la rizósfera de plantas o pueden relacionarse de manera endofítica (Harman, Howell, Viterbo y Chet, 2004). Estos hongos son componentes predominantes de la micobiota del suelo en varios ecosistemas, entre los que se incluyen los agrícolas (De Bellis, Kernaghan y Widden, 2007). Algunas especies de este género tienen importancia económica, debido a la producción de enzimas y antibióticos. También se utilizan como agentes de control biológico de enfermedades vegetales y como estimuladores del crecimiento vegetal (Harman et al., 2004; Kubicek y Penttilä, 1998).

Uno de los estudios sobre diversidad de Trichoderma/Hypocrea en el agroecosistema cacao, basados en morfología y secuencia de genes, es el de Rivas-Cordero y Pavone-Maniscalco (2010). Estos autores evaluaron la diversidad de especies de Trichoderma en la rizósfera de plantas de T. cacao L. del estado de Carabobo, Venezuela. En México, Sánchez y Rebolledo (2010) evaluaron la diversidad de Trichoderma en el agroecosistema agave tequilana, en la región de Los Altos Sur de Jalisco, México.

A pesar de la importancia de las especies del género Trichoderma, en el estado de Tabasco no existen estudios sobre el conocimiento de su biodiversidad en plantaciones de cacao. Así, en este estudio se aislaron e identificaron especies de Trichoderma presentes en la rizósfera de plantas de $T$. cacao del estado de Tabasco, y también se caracterizó la diversidad de Hypocrea/Trichoderma. Se describe la importancia económica y biotecnológica de las especies encontradas.

\section{Materiales y métodos}

El estado de Tabasco se encuentra situado al sureste de la República Mexicana entre los $17^{\circ} 15^{\prime} 00^{\prime \prime}$ - $18^{\circ} 38^{\prime} 45^{\prime \prime} \mathrm{N}$, $90^{\circ} 59^{\prime} 08^{\prime \prime}-94^{\circ} 07^{\prime} 00^{\prime \prime}$ O. En su territorio se encuentran 2 provincias fisiográficas: Llanura Costera del Golfo Sur (70\%) y Sierra de Chiapas y Guatemala (30\%). Los suelos predominantes son vertisol éutrico (433,000 ha), histosol fíbrico y asociación de gleysoles (341,078 ha) y fluvisol éutrico (245,828 ha) (LópezGüiemez et al., 2007; Palma-López, Cisneros-Domínguez, Moreno-Cáliz y Rincón-Ramírez, 2007). El clima predominante es cálido húmedo con abundantes lluvias en verano (Velázquez, 1994), temperaturas medias anuales superiores a los $26^{\circ} \mathrm{C}$ (García y Vidal-Zepeda, 1990a), con valores mínimos entre $20-22{ }^{\circ} \mathrm{C}$ en enero, y máximos entre $30-34{ }^{\circ} \mathrm{C}$ en mayo (García y Vidal-Zepeda, 1990b). La precipitación media anual es de $2,432 \mathrm{~mm}$, con periodos de precipitación y sequía definidos (CNA, 2005). Posee una superficie de aproximadamente $24,661 \mathrm{~km}^{2}$ y en ella se asientan 17 municipios que se reparten en 2 grandes regiones: Grijalva y Usumacinta. La región Grijalva se divide en 3 subregiones: la subregión de la Chontalpa, formada por los municipios de Huimanguillo, Cárdenas, Cunduacán, Comalcalco y Paraíso; la subregión Centro, integrada por los municipios de Centro, Jalpa de Méndez y Nacajuca, y la subregión Sierra, constituida por los municipios de Teapa, Jalapa y Tacotalpa. La región Usumacinta se divide en 2 subregiones: la subregión los Ríos, formada por los municipios de Balancán, Centla, Emiliano Zapata, Jonuta y Tenosique, y la subregión los Pantanos, integrada por los municipios de Macuspana, Jonuta y Centla. La entidad cuenta con una superficie de 236,812 ha para el desarrollo de la agricultura, de las cuales 41,086 ha están ocupadas con plantaciones de cacao, distribuidas en 10 municipios de las subregiones Chontalpa, Centro y Sierra, en donde la primera concentra la mayor superficie cultivada, aproximadamente el $16.38 \%$ de la superficie estatal (Sagarpa, 2000) (fig. 1).

Los sitios de muestreo se ubicaron en 3 subregiones: Chontalpa (Huimanguillo, Cárdenas, Cunduacán, Comalcalco y Paraíso), Centro (Centro, Jalpa de Méndez y Nacajuca) y Sierra (Teapa y Tacotalpa). De esta manera se consideraron los 10 municipios que concentran el total de la producción de cacao en la entidad. En cada municipio los muestreos consistieron en 3 muestras compuestas de suelo superficial $(0-20 \mathrm{~cm}$ de 


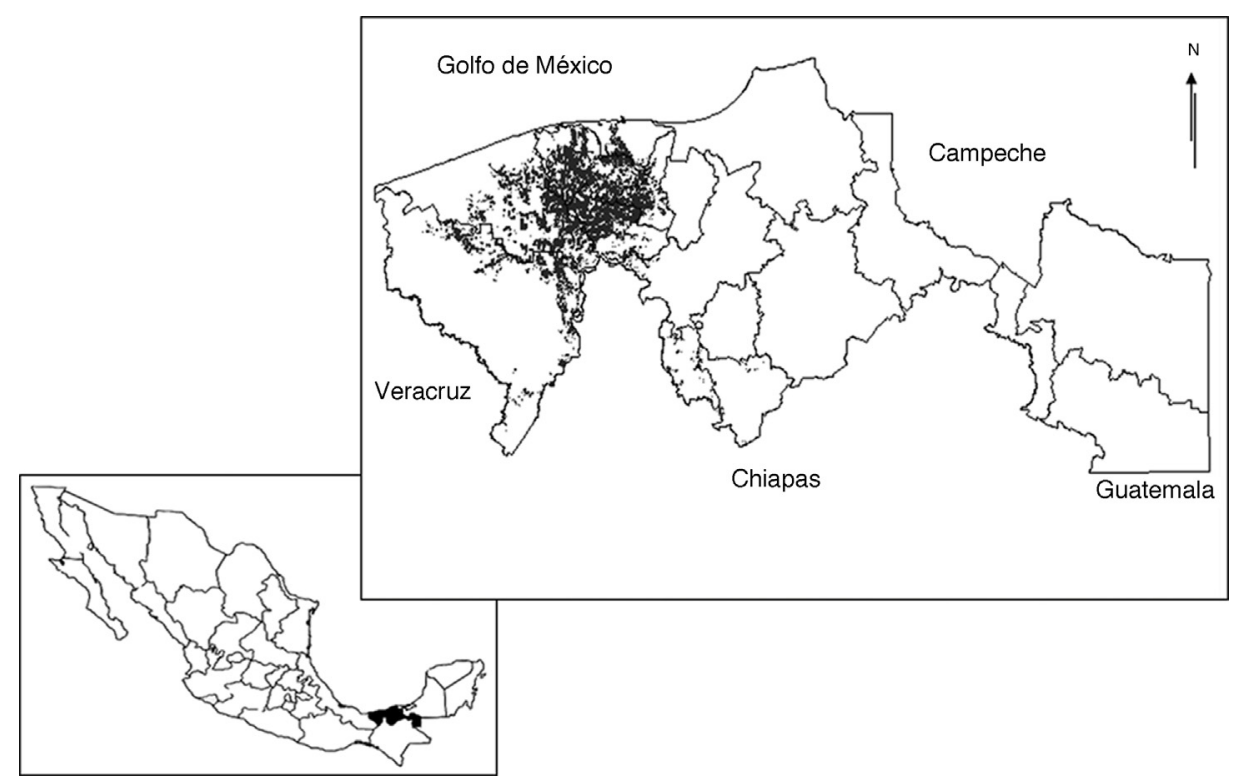

Figura 1. Ubicación del estado de Tabasco en la República Mexicana (recuadro inferior) y distribución de las plantaciones de cacao en Tabasco, México (recuadro superior).

Fuente: OEIDRUS, 2009.

profundidad). A su vez, cada muestra compuesta representó a 1 ha al considerar 5 submuestras; entonces, las 3 muestras compuestas representaron a 3 ha en cada municipio. Las coordenadas y altitud de los sitios de muestreo compuesto se aprecian en la tabla 1. El proceso de muestreo se realizó durante la época de lluvias (octubre a diciembre de 2012). Cada submuestra se recolectó de la rizósfera del árbol de T. cacao, a 1 m de distancia del tronco.

Los aislamientos de las especies de Trichoderma se obtuvieron por el método de dilución en placa (Nelson, Toussoun y Marasas, 1983), para lo cual, se diluyeron $10 \mathrm{~g}$ de suelo de cada muestra compuesta en $90 \mathrm{ml}$ de agua destilada estéril (dilución 1:10). Se prepararon 2 diluciones sucesivas (1:100 y 1:1,000), de las cuales, se dispersó una alícuota de $0.5 \mathrm{ml}$ de cada suspensión de forma uniforme sobre la superficie de una caja de Petri con el medio de cultivo agar dextrosa y papa (PDA) acidificado (1 $\mathrm{ml}$ de ácido láctico/1 1). El ácido láctico se añadió al medio de cultivo antes de vaciar en las cajas de Petri. Se prepararon 3 repeticiones por dilución utilizada. Las placas sembradas se incubaron a $25^{\circ} \mathrm{C}, 12 \mathrm{~h}$ luz/oscuridad durante 7 días. El crecimiento de Trichoderma fue reconocido por la formación de parches o cojines verdes de conidios. Las colonias visibles durante los 5 y 7 días después de la siembra se transfirieron a cajas de Petri con medio PDA y se incubaron como se mencionó anteriormente, como recomienda Michel-Aceves (2001).

Las colonias de Trichoderma se cultivaron usando la técnica de cultivos monospóricos (Estrada, Vélez y López, 1997). Los cultivos fueron almacenados a $4{ }^{\circ} \mathrm{C}$ hasta la identificación morfológica y extracción de ADN. Todos los aislamientos descritos en el presente estudio están conservados en la colección de hongos de la División Académica de Ciencias Biológicas de la Universidad Juárez Autónoma de Tabasco.

Las cepas fueron sembradas en cajas de Petri con PDA e incubadas durante 7 días, para determinar las características de la colonia: tamaño, morfología y conidiación. Además, se inoculó una suspensión de esporas sobre discos de PDA de $0.5 \mathrm{~cm}$ de diámetro, bajo un cubreobjeto, para obtener estructuras microscópicas de cada aislamiento. Todos los discos inoculados se incubaron a $25^{\circ} \mathrm{C}$ en una cámara húmeda durante 3-5 días. Las características microscópicas de conidióforos, fiálides, conidios y clamidosporas fueron observadas bajo el microscopio de campo claro y fotodocumentadas mediante digitalización de imágenes. Posteriormente, se llevó a cabo la morfometría con el software Image Tool ${ }^{\circledR} 3.00$ para Windows. Para la identificación morfológica de las especies de Hypocrea/Trichoderma se utilizó la clave interactiva de Samuels, Chaverri, Farr y McCray (2002) y ésta se confirmó con las descripciones hechas por Chaverri, Castlebury, Overton, \& Samuels (2003); Gams y Bissett (2002); Kraus et al. (2004); Park, Bae y Yu (2006); Samuels et al. (2006) y Samuels, Lieckfeldt y Nirenberg (1999).

El ADN genómico de las especies de Trichoderma se obtuvo del micelio de 5 colonias sembradas en cajas de Pietri con PDA y $72 \mathrm{~h}$ de incubación. El micelio fue homogeneizado en $400 \mu \mathrm{L}$ de buffer de extracción PBS, en un tubo Eppendorf de $1.5 \mathrm{ml}$. Seguidamente, el ADN se obtuvo siguiendo el protocolo del Kit AxyPrep Multisource Genomic ADN Minipep (Axigen ${ }^{\circledR}$ ). La calidad de ADN se evaluó en gel de agarosa al 1\% (Agarosa Ultra Pure, Invitrogen ${ }^{\circledR}$ ) y cuantificó en un espectrofotómetro Perkin Elmer ${ }^{\circledR}$ (Lambda BIO $10^{\circledR}$ ). Las regiones ITS1, ITS2 y 5.8 del ARN ribosomal se amplificaron por reacción en cadena de la polimerasa (PCR), utilizando los iniciadores universales ITS4 (TCC TCC GCT TAT TGA TAT GC) e ITS5 (GGA AGT AAA AGT CGT AAC AAG G) (White, Bruns, Lee y Taylor, 1990). La amplificación se realizó según protocolo de Ahrens y Seemüller (1992), con modificaciones en las reacciones de PCR cuyo volumen final fue de $25 \mu \mathrm{L}$ : agua ultrapura estéril $(16.05 \mu \mathrm{L})$, solución amortiguadora Buffer 10X $(2.5 \mu \mathrm{L})$, $\mathrm{MgCl}_{2}$ a $50 \mathrm{mM}(1.25 \mu \mathrm{L}), \mathrm{dNTP}$ mezcla a $10 \mathrm{mM}(0.5 \mu \mathrm{L})$, 
Tabla 1

Localización de sitios de muestreo y aislamientos de Trichoderma/Hypocrea obtenidos de la rizósfera de Theobroma cacao en Tabasco, México, 2013.

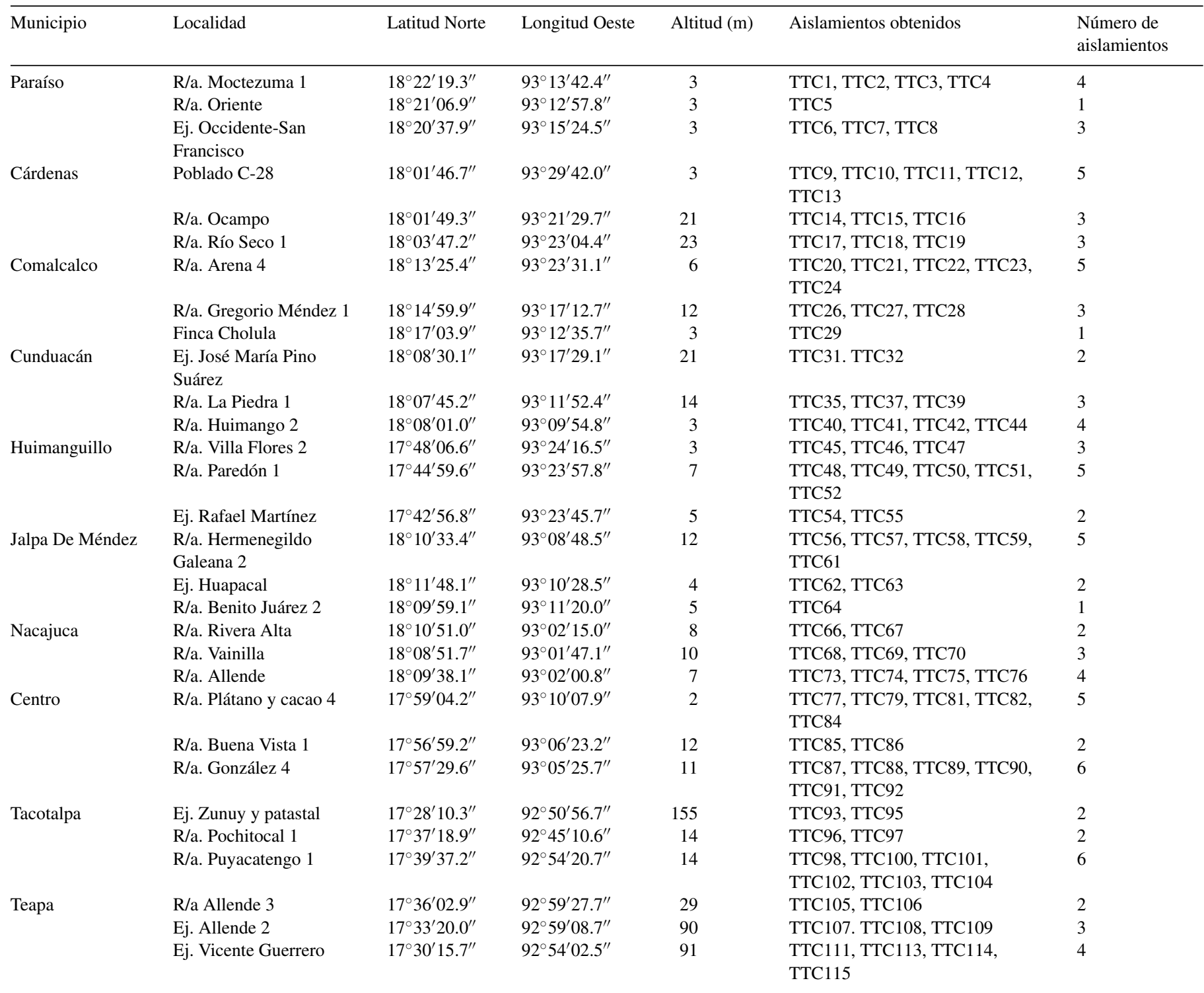

Las cepas obtenidas fueron identificadas con las siglas TTC (Trichoderma Tabasco cacao) seguidas de un número que las diferencia.

iniciadores ITS4 e ITS5 a 10 pmol (1.25 $\mu \mathrm{L}$ de cada uno), Taq DNA polimerasa (Invitrogen $\left.{ }^{\circledR}\right)$ a $1 \mathrm{U}(0.2 \mu \mathrm{L})$ y ADN blanco a $50 \mathrm{ng}(2 \mu \mathrm{L})$.

El procedimiento para la PCR consistió en los siguientes ciclos: 1 de $95^{\circ} \mathrm{C}$ por $4 \mathrm{~min}, 35$ de $95^{\circ} \mathrm{C}$ por $1 \mathrm{~min}$, 35 de $58^{\circ} \mathrm{C}$ por $1 \mathrm{~min}, 35$ de $72^{\circ} \mathrm{C}$ por $2 \mathrm{~min}$ y un ciclo de $72{ }^{\circ} \mathrm{C}$ durante $10 \mathrm{~min}$. Los productos de la PCR se sometieron a electroforesis en gel de agarosa para visualización y medida de la especificidad. La cuantificación del ADN se realizó por espectrofotometría (NanoDrop 2000, Thermo Scientific $\left.{ }^{\circledR}\right)$. Los productos fueron enviados para secuenciación a Macrogene ${ }^{\circledR}$, y las secuencias obtenidas se compararon con la base de datos del banco de genes del National Center for Biotechnology Information (NCBI, 2014) (www.ncbi.nlm.nih.gov/). Para la comparación de los valores generados con la secuencia de estudio se consideró una similitud $\geq 97 \%$ (Stackebrandt y Goebel, 1994). La sinonimia aceptada está basada en Index Fungorum (www.indexfungorum.org/), MycoBank (www.mycobank.org) y Enciclopedia de la vida (http://eol.org/pages/192915/names/synonyms).

Las secuencias de nucleótidos fueron alineadas usando el programa Crustalx 2.1 (Thompson, Gibson, Plewniak, Jeanmougin y Higgins, 1997). La inferencia filogenética fue realizada por el método neighbor-joining (NJ) (Saitou y Nei, 1987) usando el programa MEGA6 (Tamura, Stecher, Peterson, Filipski y Kumar, 2013). El soporte de las ramas en el árbol de NJ se estimó mediante el método de Bootstrap, usando 1,000 réplicas (Felsenstein, 1985). Las distancias evolutivas se estimaron usando el método $P$. distance (Nei y Kumar, 2000), excluyendo gaps y datos faltantes. Los valores de bootstrap $\geq 70 \%$ se consideraron significativos (Felsenstein, 1985). Como grupo externo 


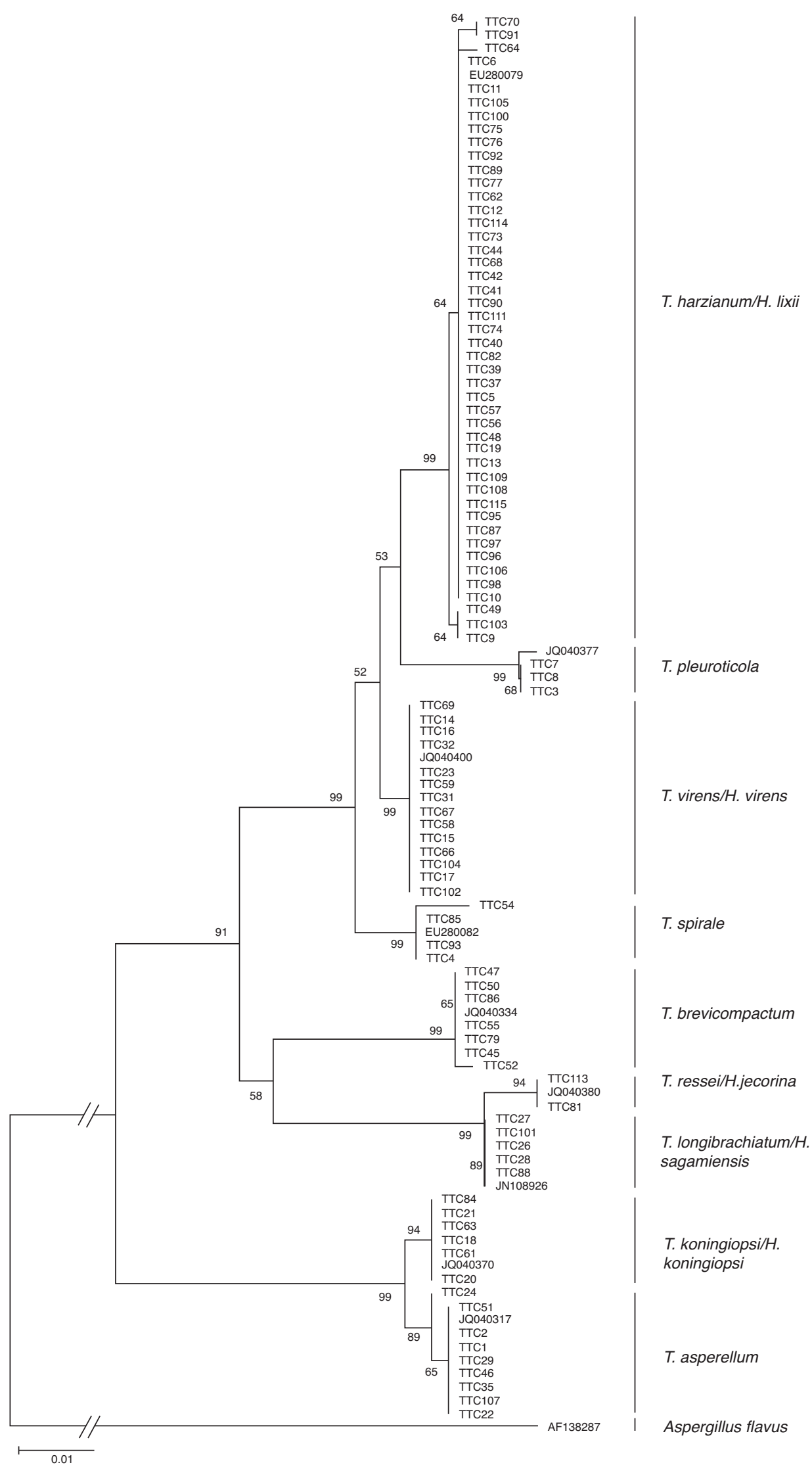

Figura 2. Relación filogenética de 96 aislamientos de Trichoderma inferido por análisis de secuencias de ADNr (ITS1, 58S y ITS2). La filogenia fue inferida por el método neighbor-joining, y la distancia evolutiva fue estimada por el método $P$. distance. Los números en los nodos representan el porcentaje del bootstrapping con 1,000 repeticiones. La barra de escala $=0.01$ sustituciones por sitio. 
Tabla 2

Especies de Trichoderma/Hypocrea presentes en la rizósfera de Theobroma cacao, identificados por morfología y amplificación de los espaciadores transcritos internos (ITS) 1 y 2, y de la región 5.8S del ARN ribosomal. Tabasco, México, 2013.

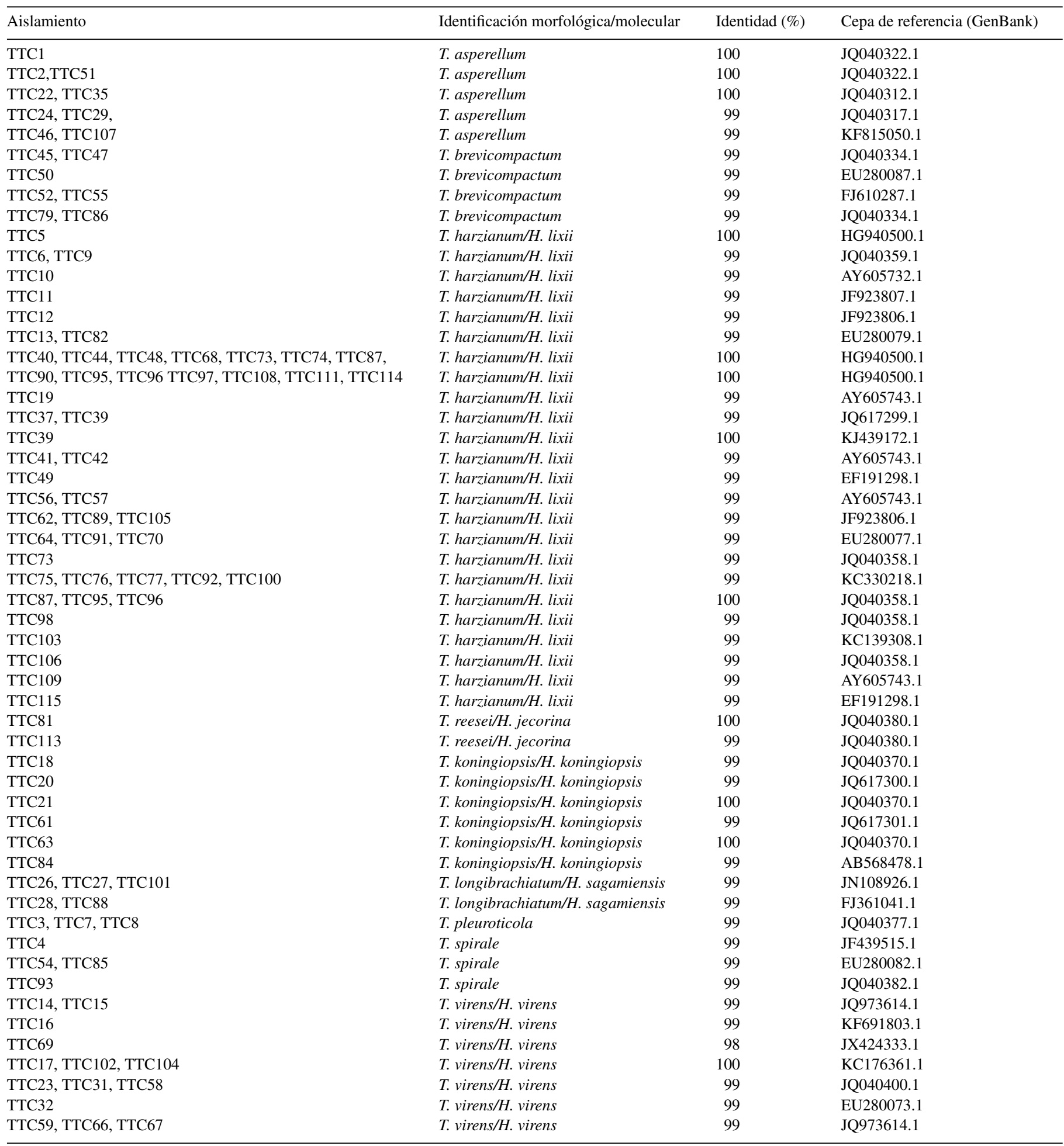

se utilizó una secuencia de Aspergillus Aspergillus flavus (número de acceso GenBank: AF138287); también se utilizaron secuencias de GenbBank de 9 especies de Trichoderma: Trichoderma harzianum (EU280079), T. pleuroticola (JQ040377), T. virens (JQ040400), T. spirale (EU280092), T. brevicompactum (JQ040334), T. reesei (JQ040380),
T. longibrachiatum (JN108926), T. koningiopsis (JQ040370) y T. asperellum (JQ040317). La elección de los grupos externos del género Trichoderma se basó en los resultados de la comparación de las secuencias de estudio con la base de datos del banco de genes del National Center for Biotechnology Information (NCBI, 2014). 
Se analizaron la riqueza específica y la abundancia de las especies de Trichoderma fueron. La riqueza específica se calculó mediante el índice de diversidad de Margalef $\left(\mathrm{D}_{\mathrm{Mg}}\right)$, por entidad y subregión:

$$
\mathrm{D}_{\mathrm{Mg}}=(\mathrm{S}-1) / \log \mathrm{N}
$$

donde $N$ es el número total de individuos y $S$ el número de especies. Este índice representa la riqueza de especies en un sentido clásico, pero en función del número total de individuos (aislamientos) obtenidos en el muestreo. La abundancia se obtuvo mediante el índice de diversidad según Shannon-Wiener:

$$
\mathrm{H}^{\prime}=-\Sigma_{\mathrm{i}} \mathrm{p}_{\mathrm{i}}\left(\log \mathrm{p}_{\mathrm{i}}\right)
$$

donde $p_{i}$ es la proporción del número total de individuos que aparece representada en la especie $i$. El índice proporciona un indicador $\left(H^{\prime}\right)$ de la relación entre el número de especies en cada subregión estudiada y sus respectivas abundancias numéricas (Magurran, 1991).

También se evaluó la equitabilidad con el índice de uniformidad de Pielou:

$$
\mathrm{J}=\mathrm{H}_{(\text {observado })}^{\prime} / \mathrm{H}_{(\mathrm{má} x)}^{\prime}
$$

donde $H^{\prime}{ }_{(m a ́ x)}$ es la diversidad máxima posible que se podría obtener si todas las especies fueran igualmente abundantes. El índice representa la uniformidad en la distribución numérica entre las diferentes especies del conjunto estudiado (Magurran, 1991).

Para comparar la composición de las comunidades fúngicas entre las subregiones incluidas en la presente investigación se obtuvo el índice de similitud de Sorensen (ISS), que se calculó con la fórmula que establece Mueller-Dombois (1981):

$$
\mathrm{ISS}=[(2 \mathrm{C}) /(\mathrm{A}+\mathrm{B}) * 100]
$$

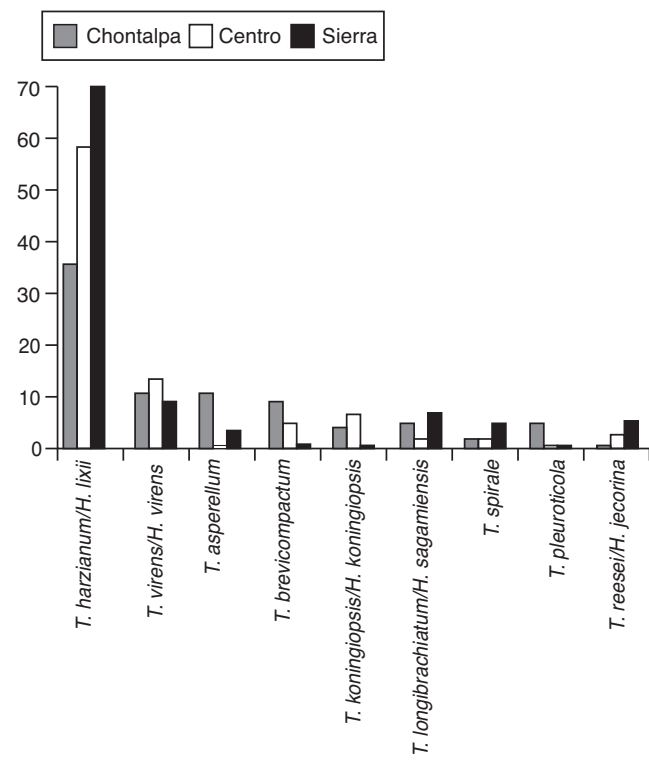

Figura 3. Riqueza de especies de Trichoderma/Hypocrea en el agroecosistema cacao, por subregión productiva, en Tabasco, México, 2013.

donde $C$ es el número de especies comunes a las 2 muestras; $A$ representa todas las especies de la primera muestra, $B$ representa todas especies de la segunda muestra.

Además, la frecuencia de constancia (FC) se calculó de acuerdo con Heredia-Abarca (1999), a fin de conocer la presencia de las especies de Trichoderma en cada subregión muestreada. Igualmente, se construyó una curva de acumulación de especies tomando como unidad de esfuerzo cada sitio de muestreo. Esta curva permitió calcular el esfuerzo de muestreo necesario para registrar el mayor número de especies posibles en el agroecosistema de estudio.

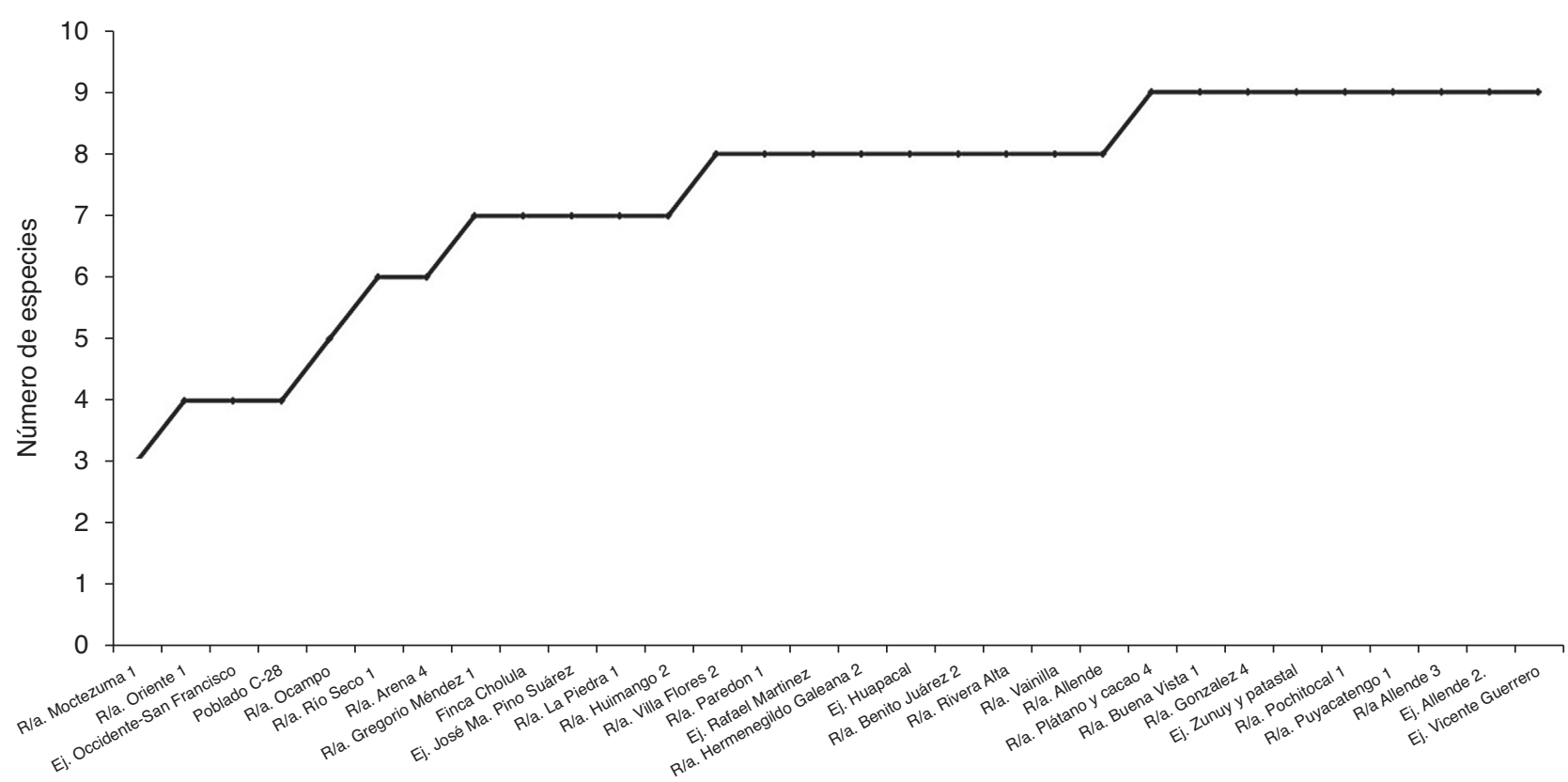

Figura 4. Curva de acumulación de especies de hongos del género Trichoderma/Hypocrea, obtenidas en el agroecosistema cacao, en Tabasco, México, 2013. 

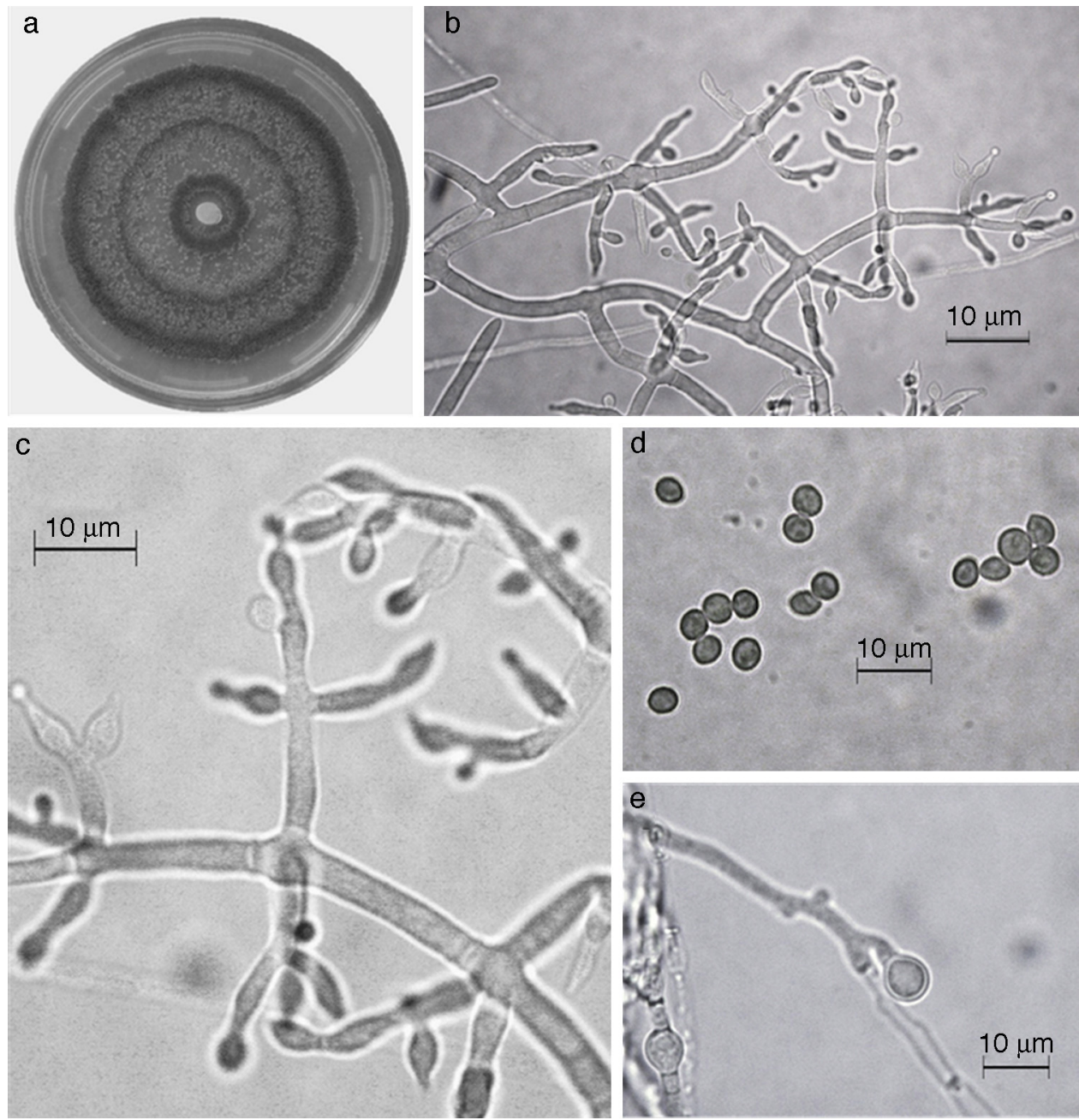

Figura 5. Trichoderma asperellum. a) colonia en medio de cultivo PDA, después de 14 días a $25^{\circ} \mathrm{C}$; b) conidióforo; c) fiálides; d) conidios; e) clamidospora. Descripción: Samuels et al. (1999); http://nt.ars-grin.gov/taxadescriptions/keys/TrichodermaIndex.cfm.

\section{Resultados}

Se obtuvieron 96 aislamientos de Trichoderma/Hypocrea a partir de muestras de suelo del agroecosistema cacao en Tabasco, México. Los aislados fueron identificados mediante morfología y secuencias de ITS, con la finalidad de conocer la riqueza y abundancia de especies (tabla 2).

En la figura 2 se muestra el árbol filogenético obtenido con las secuencias de los 96 aislamientos de Trichoderma y otras secuencias obtenidas del GeneBak. El árbol de NJ mostró 2 ramas principales: una alberga a T. koningiopsis y T. asperellum, y la otra se subdivide en otras 2 , una que alberga a $T$. longibrachiatum, T. reesei y T. brevicompactum, y la otra a T. spirale, T. virens, T. pleuroticola y T. harzianum. Con base en los soportes de las ramas de bootstrap, los 96 aislamientos de Trichoderma corresponden a 9 especies, todas ellas con soportes superiores a $89 \%$ de bootstrap (tabla 3; fig. 2). De esta manera, se determinaron 9 taxa, lo cual resultó en un $\mathrm{D}_{\mathrm{Mg}}=1.75$ y un $\mathrm{H}^{\prime}=1.69$. La mayor diversidad se detectó en la subregión Chontalpa (8 especies, $\mathrm{D}_{\mathrm{Mg}}=1.8$ ); aunque la diferencia con las subregiones restantes fue mínima: Centro (7 especies; $\mathrm{D}_{\mathrm{Mg}}=1.76$ ) y Sierra (6 especies, $\mathrm{D}_{\mathrm{Mg}}=1.7$ ) (fig. 3). La curva de acumulación de
Tabla 3

Clados formados por secuencias de ADN de aislamientos Trichoderma/Hypocrea presentes en la rizósfera de Theobroma cacao en Tabasco, México, 2013.

\begin{tabular}{llll}
\hline Clado & $\begin{array}{l}\text { Bootstrap } \\
(\%)\end{array}$ & $\begin{array}{l}\text { Núm. de } \\
\text { aislamientos }\end{array}$ & Especie \\
\hline 1 & 99 & 46 & T. harzianum/H. lixii \\
2 & 99 & 3 & T. pleuroticola \\
3 & 99 & 14 & T. virens/H. virens \\
4 & 99 & 4 & T. spirale \\
5 & 99 & 7 & T. brevicompactum \\
6 & 94 & 6 & T. reesei/H. jecorina \\
7 & 99 & 5 & T. longibrachiatum/H. sagamiensis \\
8 & 94 & 7 & T. koningiopsis/H. koningiopsis \\
9 & 89 & 8 & T. asperellum \\
\hline
\end{tabular}

especies mostró estabilidad después de 22 sitios de muestreo $\mathrm{y}$, aunque se realizaron otras exploraciones, no se localizaron nuevos taxones de este género (fig. 4).

En el presente estudio, la especie más abundante fue $T$. harzianum/H. Lixii (47.9\%), que estuvo presente en 20 de 30 sitios muestreados y que también fue dominante en 18 sitios de muestreo. Después de T. harzianum/H. lixii, T. virens/H. virens fue 

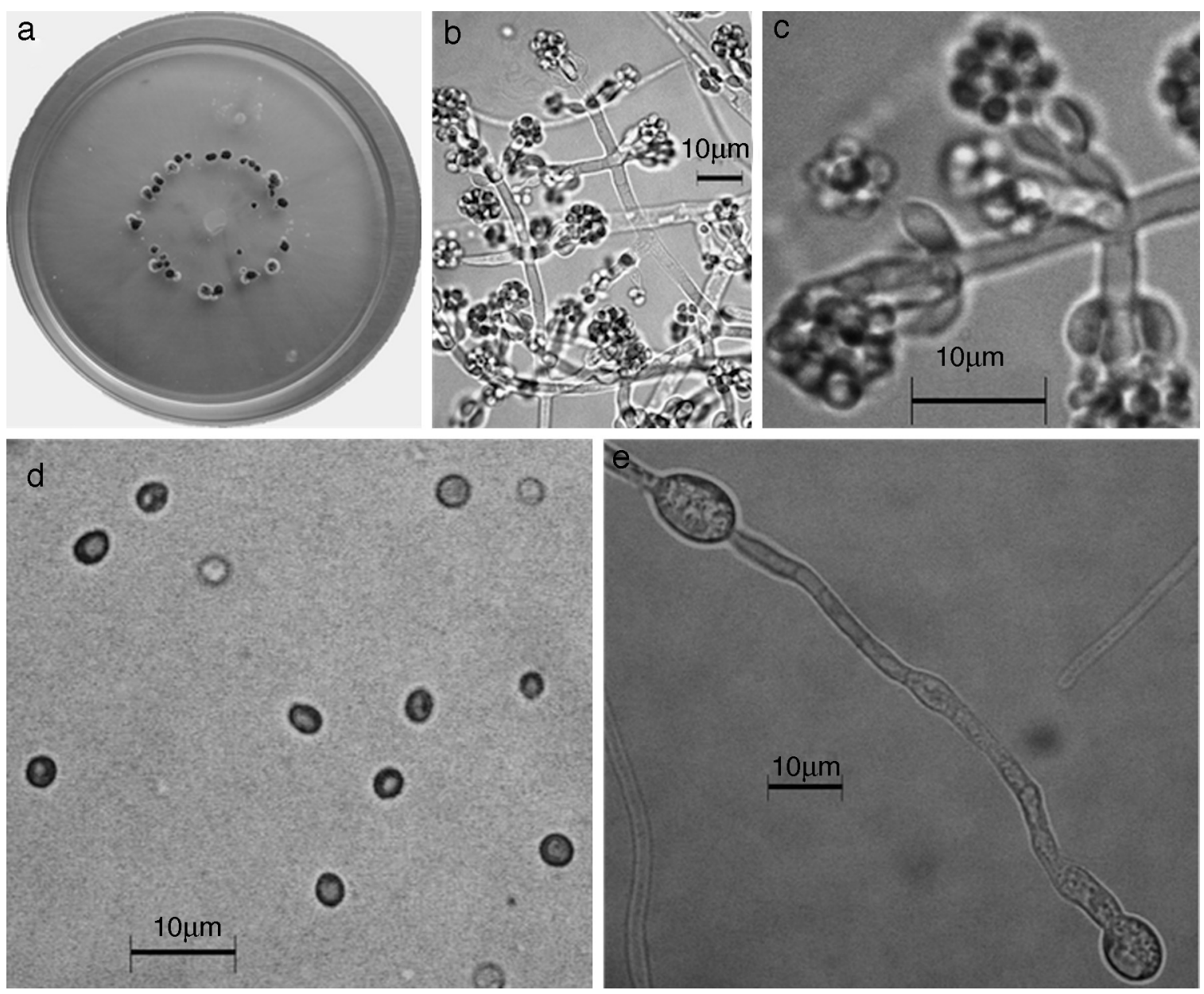

Figura 6. Trichoderma brevicompactum. a) colonia en medio de cultivo PDA, después de 14 días a $25^{\circ} \mathrm{C}$; b) conidióforo; c) fiálides; d) conidios; e) clamidospora. Descripción: Kraus et al. (2004); http://nt.ars-grin.gov/taxadescriptions/keys/TrichodermaIndex.cfm.

la especie más abundante (14.6\%), y estuvo presente en 8 de 30 sitios muestreados; sin embargo, ésta no dominó en ninguna localidad. Siete especies más se presentaron con una frecuencia inferior al 10\%: T. asperellum (9.4\%) (fig. 5), T. brevicompactum (7.3\%) (fig. 6), T. koningiopsis/H. koningiopsis (6.3\%) (fig. 7), T. longibrachiatun/H. sagamiensis $(5.2 \%)$, T. spirale $(4.2 \%)$ (fig. 8), T. pleuroticola (3.1\%) (fig. 9) y T. reesei/H. jecorina (2.1\%) (fig. 10).

El índice de uniformidad de Pielou $(J)$ fue de 0.77 . El valor de $J$ indicó uniformidad en la distribución de las especies, con dominancia de pocas especies. Considerando un mismo esfuerzo en el muestreo realizado, el número de especies $(S)$ incrementó de manera importante, desde el primer sitio $(S=3)$ hasta el sitio $13(S=8)$ (fig. 4).

En relación con el ISS, la comunidad de Trichoderma de la subregión Chontalpa fue un $88 \%$ similar a la comunidad encontrada en la subregión Centro, y de un $71.4 \%$ con la subregión de la Sierra. Así también, la comunidad de la subregión Centro fue un $76.9 \%$ similar a la subregión Sierra. Con base en la presencia de las especies en las 3 subregiones evaluadas, las especies T. harzianum/H. lixii, T. virens/H. virens, T. longibrachiatun/ $H$. sagamiensis y $T$. spirale mostraron una FC del $100 \%$. Las 4 especies restantes mostraron una FC del 67\%. La especie con menor FC en la subregión fue T. pleuroticola (tabla 4).

\section{Discusión}

Se evaluó la diversidad de Trichoderma/Hypocrea presente en la rizósfera de plantas de T. cacao en Tabasco, México. Los estudios de las especies de Trichoderma son escasos en el sureste de México. Hasta el momento presente, la identificación de especies de Hypocrea/Trichoderma requiere la combinación tanto de características morfológicas como de secuencias de algunos genes, como por ejemplo, ITS (Druzhinina y Kubicek, 2005). Basados en características morfológicas y secuenciación de las regiones ITS1 e ITS2, en el agroecosistema cacao en Tabasco, México, se identificaron 9 especies. En el sureste de México, este es el primer estudio del género Trichoderma/Hypocrea basado en un amplio número de muestras, combinadas con identificación molecular. Lo anterior limita la comparación de los resultados obtenidos de otras biocenosis.

En relación con estudios sobre diversidad de Hypocrea/Trichoderma en México, Sánchez y Rebolledo (2010), en el agroecosistema agave tequilana, en la región de Los Altos Sur de Jalisco, México, obtuvieron 4 especies de Trichoderma a partir de 66 aislados, con una $\mathrm{D}_{\mathrm{Mg}}$ de 0.71 , la cual es inferior a la obtenida en el presente estudio. De acuerdo con HoyosCarvajal y Bissett (2011), la baja diversidad de Trichoderma en algunos ecosistemas puede deberse a los disturbios agrícolas, 

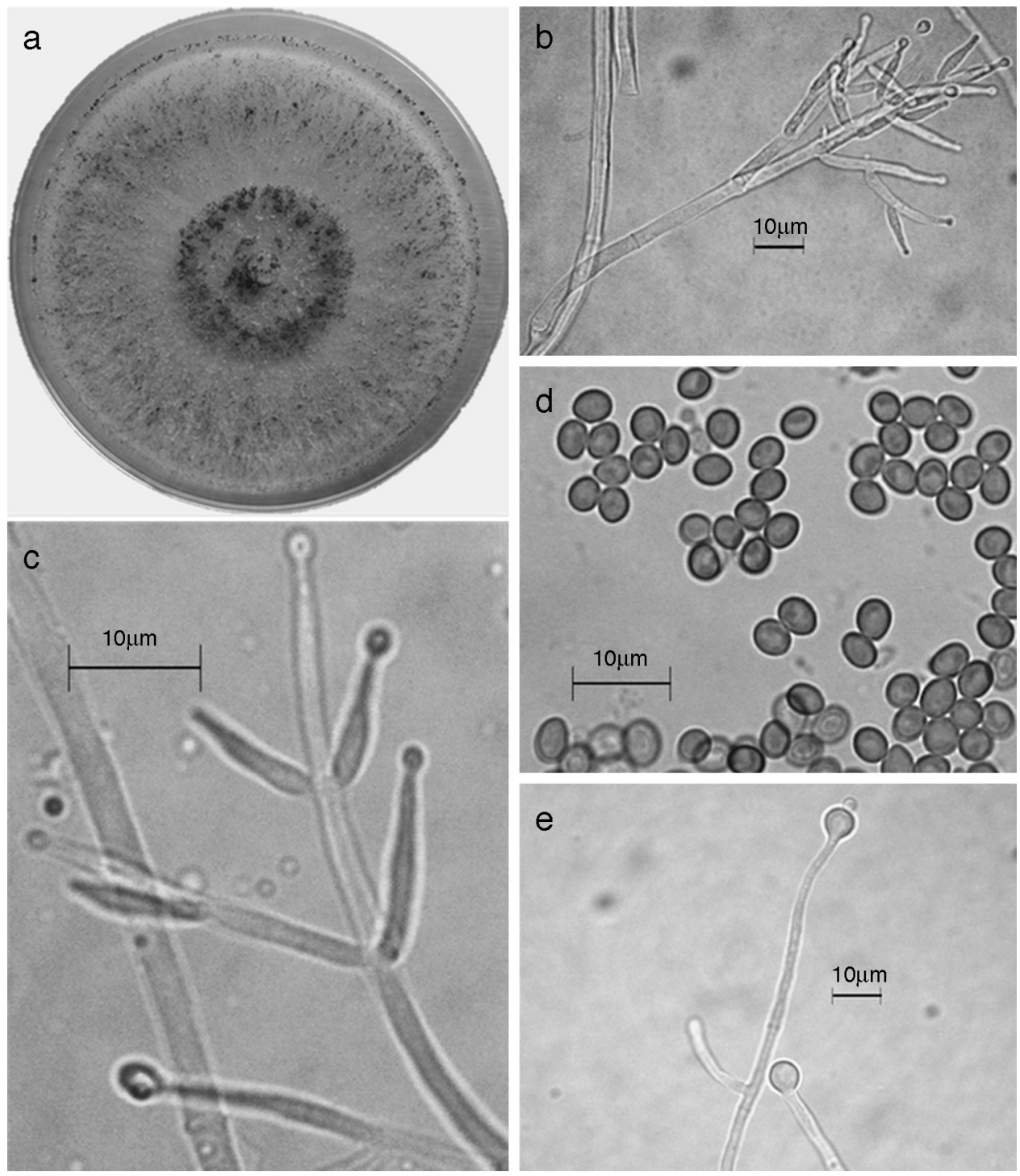

Figura 7. Trichoderma koningiopsis/H. koningiopsis. a) colonia en medio de cultivo PDA, después de 14 días a $25^{\circ} \mathrm{C}$; b) conidióforo; c) fiálides; d) conidios; e) clamidospora. Descripción: Samuels et al. (2006); http://nt.arsgrin.gov/taxadescriptions/keys/TrichodermaIndex.cfm.

por lo cual la diversidad encontrada en la presente investigación $\left(D_{\mathrm{Mg}}=1.75\right)$ refleja el efecto benéfico de un manejo conservacionista y revela las bondades del ecosistema cacao en el mantenimiento de la diversidad de este género de hongos.

En el presente estudio, la diversidad de Trichoderma/Hypocrea obtenida de la rizósfera de T. cacao fue mayor a la que documentan Rivas-Cordero y Pavone-Maniscalco (2010) en la rizósfera de plantas de T. cacao del estado de Carabobo, Venezuela. Estos autores identificaron 6 especies a partir de 35 aislados, con una $\mathrm{D}_{\mathrm{Mg}}=1.37$. Sin embargo, para América del Sur se han registrado índices relativamente mayores (10 especies/53 aislamientos, $\mathrm{D}_{\mathrm{Mg}}=2.26$; Druzhinina, Kopchinski, Komon, Bissett, Szakacs y Kubicek, 2005), el sudeste de Asia (14/96, $\mathrm{D}_{\mathrm{Mg}}=2.84$; Kubicek, Bissett, Druzhinina, Gradinger y Szakacsc, 2003), China (13/135, $\mathrm{D}_{\mathrm{Mg}}=2.44$; Zhang, Druzhinina, Kubicek y Xu, 2005) y Cerdeña (isla del mar Mediterráneo) $\left(14 / 482, \mathrm{D}_{\mathrm{Mg}}=2.1\right.$; Migheli et al., 2009).
La estabilidad mostrada por la curva de acumulación de especies indicó que el número de especies registradas en este trabajo es muy cercano al que alberga el agroecosistema muestreado, en la rizósfera, en el estado de Tabasco, y que el esfuerzo de muestreo que falta por realizar para obtener otras especies es poco (fig. 4).

Los resultados del presente estudio muestran la predominancia de T. harzianum/H. lixii/, similar a lo obtenido por Rivas-Cordero y Pavone-Maniscalco (2010) para el agroecosistema cacao del estado de Carabobo, Venezuela. Sin embargo, otros estudios también evidencian la predominancia de esta especie (Kullnig, Szakacs y Kubicek, 2000; Wuczkowski, Druzhinina, Gherbawy, Klug, Prillinger y Kubicek, 2003; Zhang et al., 2005).

En relación con la presencia de las especies en las subregiones evaluadas, $T$. harzianum $/ H$. lixii, $T$. virens/H. virens, T. longibrachiatun/H. sagamiensis y $T$. spirale estuvieron presentes en las 3 subregiones donde se cultiva cacao en Tabasco; 

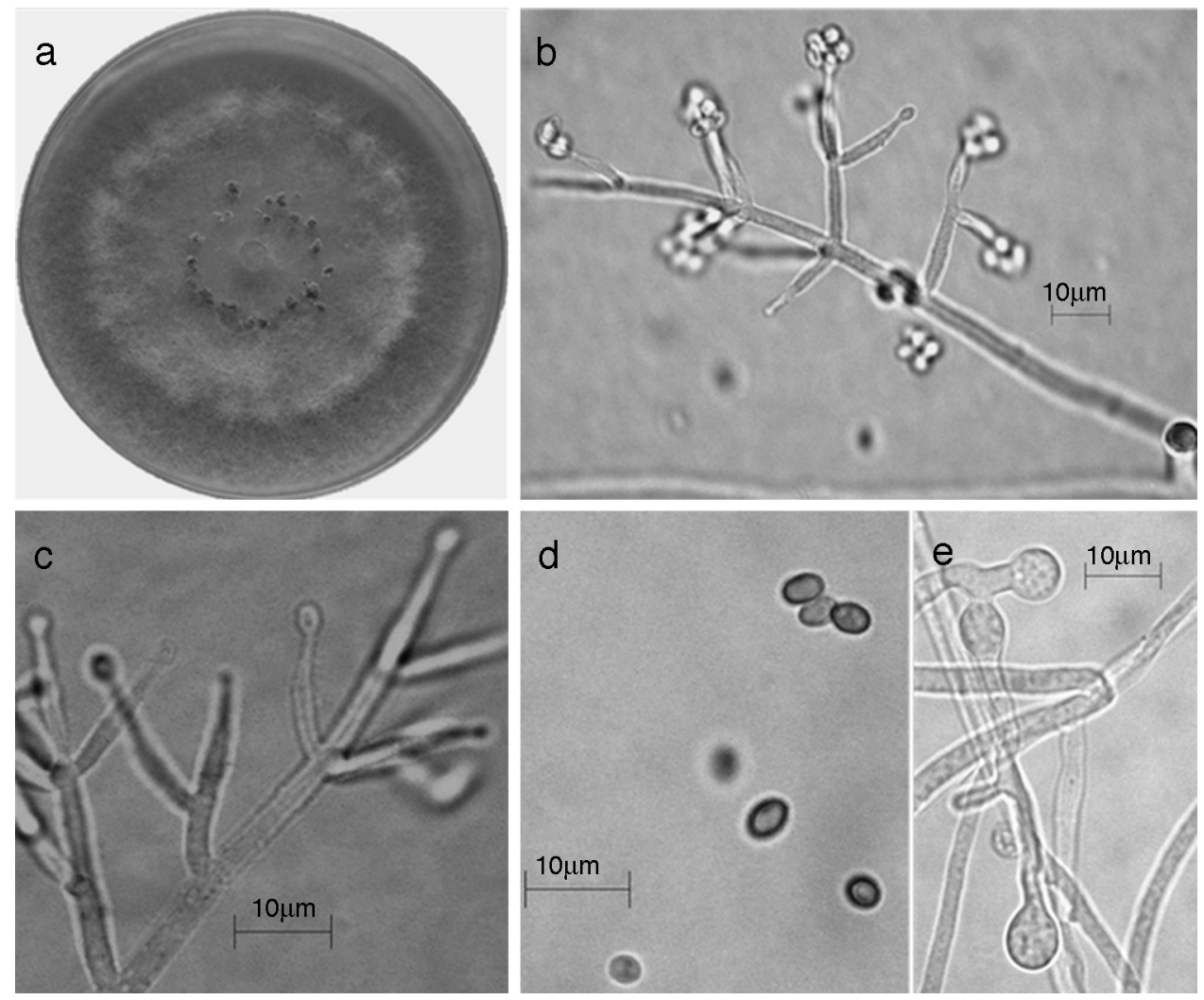

Figura 8. Trichoderma spirale (Synanamorfo). a) colonia en medio de cultivo PDA, después de 14 días a $25^{\circ} \mathrm{C}$, con abundante micelio aéreo; b) conidióforo; c) fiálides; d) conidios; e) clamidospora. Descripción: Chaverri, Castlebury, Overton y Samuels (2003); http://nt.arsgrin.gov/taxadescriptions/keys/TrichodermaIndex.cfm.

sin embargo, T. brevicompactum y T. koningiopsis/H. koningiopsis sólo se encontraron en la región de la Chontalpa y Centro. Todas las especies encontradas en la subregión de la Sierra se presentaron en la subregión de la Chontalpa, excepto T. reesei. Trichoderma pleuroticola únicamente se presentó en la subregión de la Chontalpa (tabla 4). La mayor riqueza de especies se encontró en la subregión de la Chontalpa, que alberga la mayor superficie cultivada con T. cacao (OEIDRUS, 2009)

Las 9 especies de Trichoderma/Hypocrea encontradas en el presente estudio constituyen el primer registro para el agroecosistema cacao en el estado de Tabasco. Así también, T. asperellum (fig. 5), T. brevicompactum (fig. 6), T. koningiopsis/H. koningiopsis (fig. 7), T. spirale (fig. 8), T. pleuroticola (fig. 9) y $T$. reesei/H. jecorina (fig. 10) son nuevos registros para la entidad; y T. pleuroticola (fig. 9) es un registro nuevo para México.

De las especies de Trichoderma/Hypocrea encontradas en el presente estudio, T. brevicompactum, T. harzianum/H. lixii, T. koningiopsis/H. koningiopsis y $T$. virens/H. virens se han registrado en el agroecosistema cacao en Venezuela (Rivas-Cordero y Pavone-Maniscalco, 2010). También, T. harzianum/H. lixii, T. longibrachiatun/H. sagamiensis y $T$. reesei/H. jecorina se registraron por Sánchez y Rebolledo (2010) en el agroecosistema agave tequilana en Jalisco, México. En Tabasco, Del Olmo-Ruiz, Cifuentes-Blanco, Vidal-Gaona y Rosique-Gil (2010) documentaron la presencia de $T$. harzianum/H. lixii y $T$. longibrachiatun/H. sagamiensis en una plantación de plátano (Musa paradisiaca).
De las especies encontradas en este estudio, T. asperellum, $T$. harzianum/H. lixii, T. longibrachiatun/H. sagamiensis, T. virens/ $H$. virens, T. spirale y T. koningiopsis/H. koningiopsis son especies que tienen aplicación como agentes de control biológico de hongos fitopatógenos (Evans, Holmes y Thomas, 2003; Hjeljord y Tronsmo, 1998; Krauss y Soberanis, 2001). De manera particular, T. harzianum/H. lixii y $T$. virens/H. virens son especies utilizadas para el control de Phytophthora palmivora y Moniliophthora roreri, 2 hongos patógenos del cacao (Benítez, Rincón, Limón y Codón, 2004; Evans et al., 2003; Harman, 2000; Krauss y Soberanis, 2001; Migheli, Whipps, Budge y Lynch, 1995). También $T$. virens/H. virens se ha registrado como promotor del crecimiento en algunas especies vegetales (Contreras-Cornejo, Macías-Rodríguez, Cortés-Penagos y López-Bucio, 2009), y T. asperellum es capaz de colonizar el sistema radical de algunas especies vegetales e inducir resistencia a patógenos (Yerdidia et al., 2003). Trichoderma pleuroticola es el agente causal de pérdidas de producción en cultivos de hongos comestibles (Sobieralski et al., 2012). Trichoderma reesei/ $H$. jecorina es un hongo de importancia económica debido a su alta capacidad de producción de enzimas industriales (Kubicek y Penttilä, 1998). Trichoderma brevicompactum se ha registrado como productor de antibióticos (Degenkolb, Gräfenhan, Nirenberg, Gams y Brückner, 2006). Finalmente, T. longibrachiatun/H. sagamiensis tiene importancia agronómica y biotecnológica, por ejemplo en la producción de las enzimas celulasa, glucanasas e hidrolasas; además, es un patógeno oportunista en humanos inmunocomprometidos (Kredics et al., 2003). 

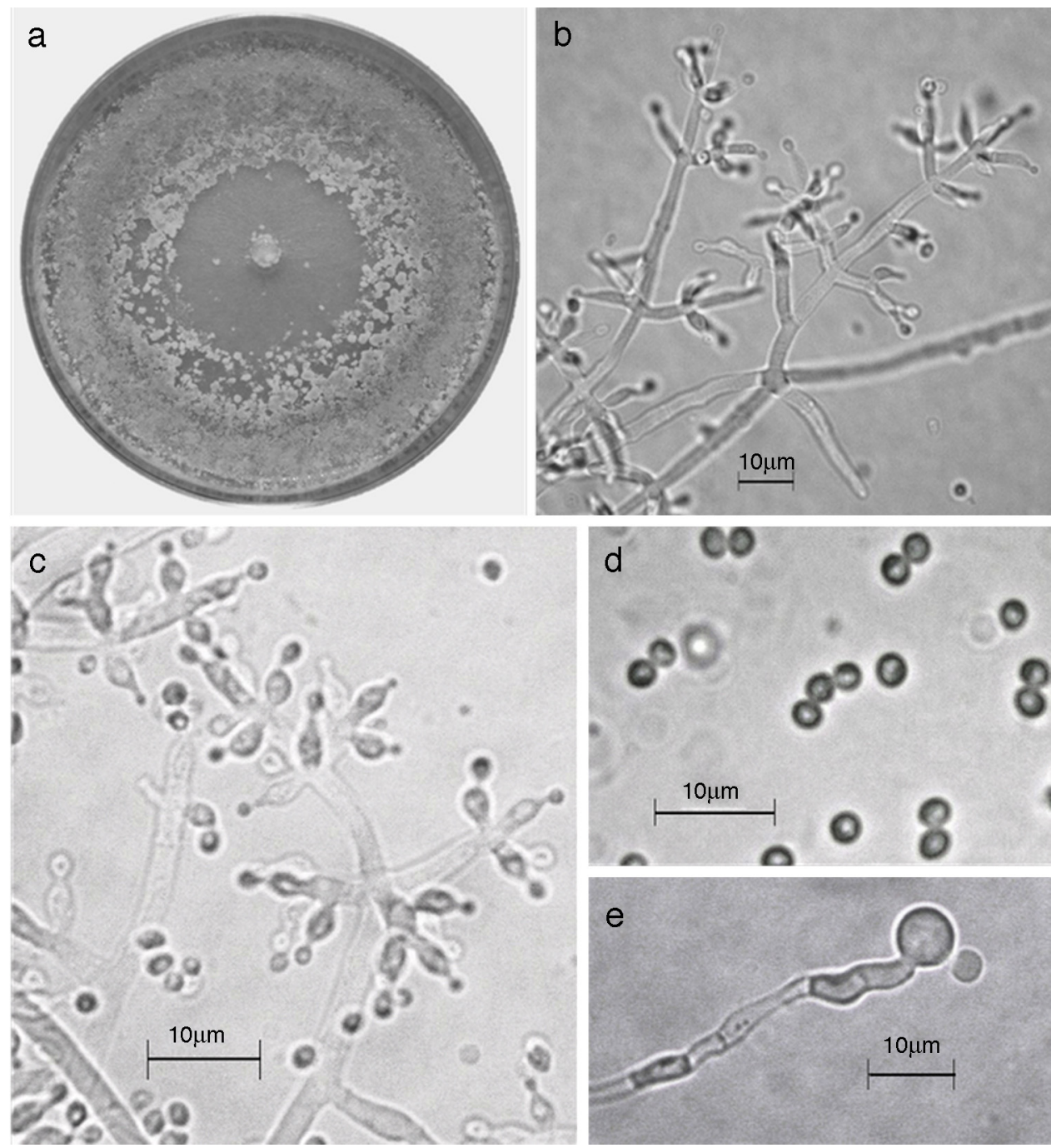

Figura 9. Trichoderma pleuroticola. a) Colonia en medio de cultivo PDA después de 14 días a $25^{\circ} \mathrm{C}$; b) conidióforo; c) fiálides; d) conidios; e) clamidospora. Descripción: Park et al. (2006); http://nt.ars-grin.gov/taxadescriptions/keys/TrichodermaIndex.cfm.

Los resultados de este trabajo, incluyendo el índice de diversidad de Shannon-Wiener y de equitatividad de Pielou, servirán como referencia para futuras investigaciones sobre la ecología de las especies del género Trichoderma. Además, los resultados obtenidos demuestran la alta diversidad de especies de Trichoderma/Hypocrea que pueden encontrarse en ambientes poco perturbados. Así también, este estudio revela que el agroecosistema cacao es un área de investigación con potencial biotecnológico. Asimismo, el conocimiento de la diversidad de Trichoderma y la obtención de aislados regionales forman el primer paso en la búsqueda de agentes de control de enfermedades vegetales. La utilidad potencial de los aislamientos y especies obtenidas en el control biológico de diversas enfermedades puede evaluarse en futuras investigaciones.

Tabla 4

Especies de Trichoderma/Hypocrea presentes en la rizósfera de Theobroma cacao y su frecuencia de constancia por subregión. Tabasco, México, 2013.

\begin{tabular}{llllr}
\hline Especies & & Subregiones & Frecuencia de constancia $(\%)$ \\
\cline { 2 - 4 } & Chontalpa & Centro & Sierra \\
\hline T. harzianum/H. Lixii & 1 & 1 & 1 & 100 \\
T. virens/H. virens & 1 & 1 & 1 & 100 \\
T. asperellum & 1 & 0 & 1 & 67 \\
T. brevicompactum & 1 & 1 & 0 & 67 \\
T. koningiopsis/H. koningiopsis & 1 & 1 & 0 & 67 \\
T. longibrachiatum/H. sagamiensis & 1 & 1 & 1 & 100 \\
T. spirale & 1 & 1 & 1 & 33 \\
T. pleuroticola & 1 & 0 & 0 & 67 \\
T. reesei/H. jecorina & 0 & 1 & 1 & \\
\hline
\end{tabular}



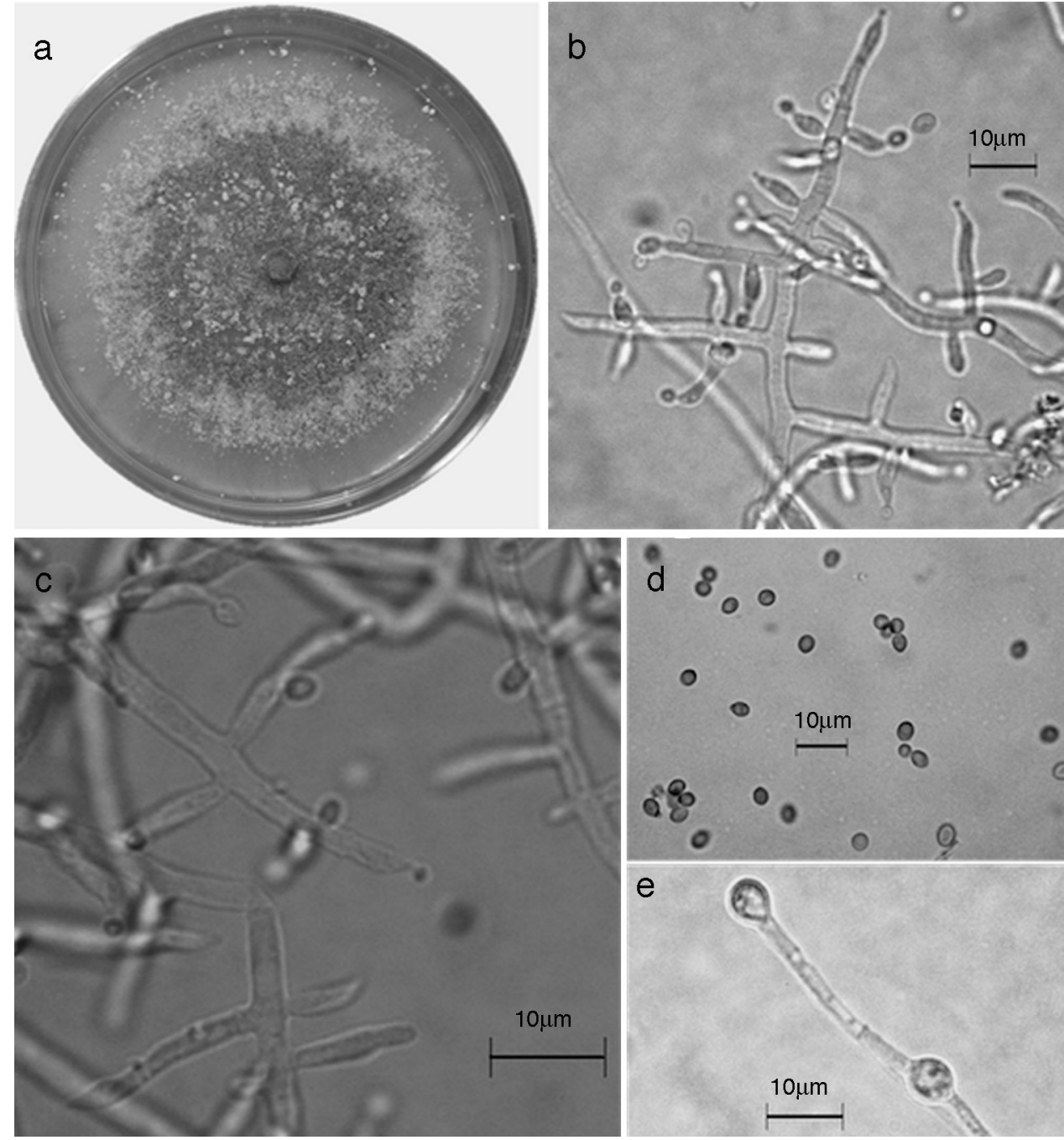

Figura 10. Trichoderma reesei/H. jecorina. a) colonia en medio de cultivo PDA, después de 14 días a $25^{\circ} \mathrm{C}$; b) conidióforo; c) fiálides; d) conidios; e) clamidospora. Descripción: Gams y Bissett (2002); http://nt.ars-grin.gov/taxadescriptions/keys/TrichodermaIndex.cfm.

\section{Agradecimientos}

Este trabajo fue llevado a cabo con el financiamiento otorgado por el Programa de Mejoramiento del Profesorado (PROMEP) de la Secretaría de Educación Pública, México, y el proyecto (Conacyt) CB-2008-01-106570: Estudio etiológico, epidemiológico y de formas de control de Moniliophthora roreri, agente causal de la moniliasis del cacao, en México.

\section{Referencias}

Ahrens, U. y Seemüller, E. (1992). Detection of DNA of plant pathogenic mycoplasmalike organisms by a polymerase chain reaction that amplifies a sequence of the $16 \mathrm{~S}$ rDNA gene. Phytopathology, 82, 828-832.

Benítez, T., Rincón, A. M., Limón, M. C. y Codón, A. C. (2004). Biocontrol mechanisms of Trichoderma strains. International Microbiology, 7 , 249-260.

Chaverri, P., Castlebury, L. A., Overton, B. E. y Samuels, G. J. (2003). Hypocrea/Trichoderma: species with conidiophores elongations and green conidia. Mycologia, 95, 1100-1140.

CNA (Comisión Nacional de Agua). (2005). Productos climatológicos. Servicio Meteorológico Nacional. Recuperado el 2 de septiembre de 2013 de: http://smn.cna.gob.mx
Contreras-Cornejo, H., Macías-Rodríguez, L., Cortés-Penagos, C. y LópezBucio, J. (2009). Trichoderma virens, a plant beneficial fungus, enhances biomass production and promotes lateral root growth through an auxindependent mechanism in Arabidopsis. Plant Physiology, 149, 1579-1592.

Córdova-Ávalos, V., Sánchez-Hernández, M., Estrella-Chulím, N. G., MacíasLayalle, A., Sandoval-Castro, E. y Ortiz-García, C. F. (2001). Factores que afectan la producción de cacao (Theobroma cacao L.) en el ejido Francisco I. Madero del Plan Chontalpa, Tabasco, México. Universidad y Ciencia, 17, 93-100.

De Bellis, T., Kernaghan, G. y Widden, P. (2007). Plant community influences on soil microfungal assemblages in boreal mixed-wood forests. Mycologia, 99, 356-367.

Degenkolb, T., Gräfenhan, T., Nirenberg, H., Gams, W. y Brückner, H. (2006). Trichoderma brevicompactum complex: rich source of novel and recurrent plant-protective polypeptide antibiotics (peptaibiotics). Journal of Agricultural and Food Chemistry, 54, 7047-7061.

Del Olmo-Ruiz, M., Cifuentes-Blanco, J., Vidal-Gaona, G. y Rosique-Gil, E. (2010). Micromicetos del suelo de una plantación de plátano (Musa paradisiaca) en Teapa, Tabasco, México. Revista Mexicana de Biodiversidad, 8, 97-102.

Druzhinina, I. y Kubicek, C. (2005). Species concepts and biodiversity in Trichoderma and Hypocrea: from aggregate species to species clusters. Journal Zhejiang University Science, 6, 100-112.

Druzhinina, I., Kopchinski, A., Komon, M., Bissett, J., Szakacs, G. y Kubicek, C. (2005). An oligonucleotide barcode for species 
identification in Trichoderma and Hypocrea. Fungal Genetics and Biology, 42, 813-828.

Estrada, V., Vélez, A. y López, J. (1997). Estandarización de una metodología para obtener cultivos monospóricos del hongo Beauveria bassiana. Cenicafé, 48, 59-65.

Evans, H. C., Holmes, K. A. y Thomas, S. E. (2003). Endophytes and mycoparasites associated with an indigenous forest tree, Theobroma gileri, in Ecuador and a preliminary assessment of their potential as biocontrol agents of cocoa diseases. Mycological Progress, 2, 149-160.

Felsenstein, J. (1985). Confidence limits on phylogenies: an approach using the bootstrap. Evolution, 39, 783-791.

Gams, W. y Bissett, J. (2002). Morphology and identification of Trichoderma. En C. P. Kubicek y G. F. Hamman (Eds.), Trichoderma and Gliocladium (Vol. 1) (pp. 3-34). London: Taylor and Francis.

García, E. y Vidal-Zepeda, R. (1990a). “Temperatura media”, Atlas Nacional de México, Hoja IV.4.4. México, D.F.: Instituto de Geografía, Universidad Nacional Autónoma de México.

García, E. y Vidal-Zepeda, R. (1990b). "Temperaturas extremas”, Atlas Nacional de México, Hoja IV.4.5. México, D.F.: Instituto de Geografía, Universidad Nacional Autónoma de México.

Greenberg, R., Bichier, P. y Cruz, A. A. (2000). The conservation value for birds of cacao plantations with diverse planted shade in Tabasco, Mexico. Animal Conservation, 3, 105-112.

Harman, G. E. (2000). Myths and dogmas of biocontrol: changes in perceptions derive from research on Trichoderma harzianum T-22. Plant Disease, 84, 377-393.

Harman, G. E., Howell, C. R., Viterbo, A. y Chet, I. (2004). Trichoderma spp.opportunistic avirulent plant symbionts. Nature Reviews Microbiology, 2, 43-56.

Heredia-Abarca, G. P. (1999). Diversidad y sucesión de los hyphomycetes de la superficie de las hojas en descomposición de tres especies arbóreas dominantes en un bosque mesófilo de montaña en el centro de Veracruz. Tesis Doctoral. Facultad de Ciencias, Universidad Nacional Autónoma de México.

Hjeljord, L. y Tronsmo, A. (1998). Trichoderma and Gliocladium in biological control: an overview. En G. E. Harman y C. P. Kubicek (Eds.), Trichoderma and Gliocladium. Vol. 2. Enzymes, biological control, and commercial applications (pp. 131-151). London: Taylor and Francis.

Hoyos-Carvajal, L. y Bissett, J. (2011). Biodiversity of Trichoderma in Neotropics. The dynamical processes of biodiversity-Case studies of evolution and spatial distribution. Recuperado el 28 de agosto de 2013 de: http://intechopen.com

Ibarra, A. C., Arriaga, S. y Estrada, A. (2001). Avifauna asociada a dos cacaotales tradicionales en la región de la Chontalpa, Tabasco, México. Universidad y Ciencia, 34, 101-112.

Klein, D. y Eveleigh, E. (1998). Ecology of Trichoderma. En C. P. Kubicek y G. E. Harman (Eds.), Trichoderma and Gliocladium. Basic biology, taxonomy and genetics (pp. 57-74). London: Taylor and Francis.

Krauss, U. y Soberanis, W. (2001). Rehabilitation of diseased cacao fields in Peru through shade regulation and timing of biocontrol measures. Agroforestry System, 53, 179-218.

Kraus, G. F., Druzhinina, I., Gams, W., Bissett, J., Zafari, D., Szakacs, G., et al. (2004). Trichoderma brevicompactum sp. nov. Mycologia, 96, 1059-1073.

Kredics, L., Antal, Z., Dóczi, I., Manczinger, L., Kevei, F. y Nagy, E. (2003). Clinical importance of the genus Trichoderma. A review. Acta Microbiologica et Immunologica Hungarica, 50, 105-117.

Kubicek, C. P. y Penttilä, M. E. (1998). Regulation of production of plant polysaccharide degrading enzymes by Trichoderma. En G. E. Harman y C. P. Kubicek (Eds.), Trichoderma and Gliocladium. Vol. 2. Enzymes, biological control and commercial applications (pp. 49-71). London: Taylor and Francis.

Kubicek, C., Bissett, J., Druzhinina, I., Gradinger, C. y Szakacs, G. (2003). Genetic and metabolic diversity of Trichoderma: a case study on South-East Asian isolates. Fungal Genetics and Biology, 38, 310-319.

Kullnig, C. M., Szakacs, G. y Kubicek, C. P. (2000). Molecular identification of Trichoderma species from Russia. Siberia and the Himalaya. Mycology Research, 104, 1117-1125.
López-Güemez, A. R., Palma-González, B., Hernández-Rivera, M. A., OjedaMorales, M. E., Ángeles-Padilla, A., Ruiz Nájera, J. A., et al. (2007). Caracterización fisicoquímica de los suelos predominantes en el estado de Tabasco. Conciencia Tecnológica, 7, 45-46.

Magurran, A. E. (1991). Ecological diversity and its measurement. London: Chapman and Hall.

Michel-Aceves, A. C. (2001). Cepas nativas de Trichoderma spp. Euascomycetes Hypocreales. Su antibiosois y micoparasitismo sobre Fusarium subglutinans y F. oxisporum (Hyphomicetes: Hyphales). Tesis doctoral. Universidad de Colima.

Migheli, Q., Balmas, V., Komon-Zelazowska, M., Scherm, B., Fiori, S., Kopchinskiy, A. G., et al. (2009). Soils of a Mediterranean hot spot of biodiversity and endemism (Sardinia, Tyrrhenian Islands) are inhabited by pan-european, invasive species of Hypocrea/Trichoderma. Environmental Microbiology, 11, 35-46.

Migheli, Q., Whipps, J. M., Budge, S. P. y Lynch, J. M. (1995). Production of inter and intra strain hybrids of Trichoderma spp. by protoplast fusion and evaluation of their biocontrol activity against soil-borne and foliar pathogens. Journal of Phytopathology, 143, 91-97.

Mueller-Dombois, D. (1981). Ecological measurements and microbial populations. En D. T. Wicklow y G. C. Carroll (Eds.), The fungal community. Its organization and role in the ecosystem (pp. 123-184). New York: Marcel Dekker.

Muñoz, D., Estrada, A. y Naranjo, E. (2005). Monos aulladores (Alouatta palliata) en una plantación de cacao (Theobroma cacao) en Tabasco, México: aspectos de la ecología alimentaria. Universidad y Ciencia, 2, 35-44.

NCBI (National Center for Biotechnology Information). (2014). Recuperado el 14 de julio de 2014 de: http://ncbi.nlm.nih.gov

Nei, M. y Kumar, S. (2000). Molecular evolution and phylogenetics. New York: Oxford University Press.

Nelson, P. E., Toussoun, T. A. y Marasas, W. F. O. (1983). Fusarium species: an illustrated manual for identification. Pennsylvania: Pennsylvania State University Press, University Park.

OEIDRUS (Oficina Estatal de Información para el Desarrollo Rural Sustentable en el Estado de Tabasco). (2009). Recuperado el 15 de agosto de 2013 de: http://oeidrustab.gob.mx

Palma-López, D. J., Cisneros-Domínguez, J., Moreno-Cáliz, E. y RincónRamírez, J. A. (2007). Suelos de Tabasco: su uso y manejo sustentable. Villahermosa: Colegio de Postgraduados-ISPROTAB-FUPROTAB.

Park, M. S., Bae, K. S. y Yu, S. H. (2006). Two new species of Trichoderma associated with green mold of oyster mushroom cultivation in Korea. Mycobiology, 34, 111-113.

Pérez-De la Cruz, M., Sánchez-Soto, S., Ortiz-García, C. F., Zapata-Mata, S. y De la Cruz-Pérez, A. (2007). Diversidad de insectos capturados por arañas tejedoras (Arachnida: Araneae) en el agroecosistema cacao en Tabasco, México. Neotropical Entomology, 36, 90-101.

Pérez-De la Cruz, M., Equihua-Martínez, A., Romero-Nápoles, J., SánchezSoto, S., García-López, E. y Bravo-Mojica, H. (2009). Escolítidos (Coleoptera: Scolytidae) asociados al agroecosistema cacao en Tabasco, México. Neotropical Entomology, 38, 1-8.

Rice, R. A. y Greenberg, R. (2000). Cacao cultivation and the conservation of biological diversity. Ambio, 3, 167-176.

Rivas-Cordero, M. y Pavone-Maniscalco, D. (2010). Diversidad de Trichoderma spp. en plantaciones de Theobroma cacao L. del estado Carabobo, Venezuela, y su capacidad biocontroladora sobre Crinipellis perniciosa (Stahel) Singer. Interciencia, 35, 777-783.

Rivas-Rojas, E. S. (2005). Diversity bats of dry forest and cocoa plantation. Lyonia, 8, 29-39.

Saitou, N. y Nei, M. (1987). The neighbor-joining method: a new method for reconstructing phylogenetic trees. Molecular Biology and Evolution, 4 , 406-425.

Sagarpa (Secretaría de Agricultura, Ganadería, Desarrollo Rural, Pesca y Alimentación). (2000). Análisis de la situación comercial del cacao en Tabasco. Villahermosa: Sagarpa. Delegación Estatal de Tabasco.

Samuels, G. J., Lieckfeldt, E. y Nirenberg, H. I. (1999). Trichoderma asperellum, a new species with warted conidia, and redescription of T. viride. Sydowia, 51, 71-88. 
Samuels, G. J., Chaverri, P., Farr, D. F. y McCray, E. B. (2002). Trichoderma online. Systematic mycology and microbiology laboratory, ARS, USDA. Recuperado el 10 de agosto de 2013 de: http://nt.ars-grin.gov

Samuels, G. J., Dodd, S. L., Lu, B. S., Petrini, O., Schroers, H. J. y Druzhinina, I. (2006). The Trichoderma koningii aggregate species. Studies in Mycology, $56,67-133$.

Sánchez, V. y Rebolledo, O. (2010). Especies de Trichoderma en suelos cultivados con Agave tequilana en la región de Los Altos Sur, Jalisco y valoración de su capacidad antagónica contra Thielaviopsis paradoxa. Revista Mexicana de Micología, 32, 11-18.

Sobieralski, K., Siwulski, M., Komon-Zelazowska, M., Błaszczyk, L., Górski, R., Spiżewski, T., et al. (2012). Evaluation of the growth of Trichoderma pleurotum and Trichoderma pleuroticola isolates and their biotic interaction with Pleurotus sp. Journal of Plant Protection Research, 52, 235-239.

Stackebrandt, E. y Goebel, B. M. (1994). Taxonomic note: a place for DNADNA reassociation and 16S rRNA sequence analysis in the present species definition in bacteriology. International Journal of Systematic Bacteriology, 44, 846-849.

Tamura, K., Stecher, G., Peterson, D., Filipski, A. y Kumar, S. (2013). MEGA6: Molecular evolutionary genetics analysis. Version 6.0. Molecular Biology and Evolution, 30, 2725-2729.

Thompson, J. D., Gibson, T. J., Plewniak, F., Jeanmougin, F. y Higgins, D. G. (1997). The Clustal X windows interface: flexible strategies for multiple sequence alignment aided by quality analysis tools. Nucleic Acids Research, $24,4876-4882$

Vandermeer, J. H. (2003). Agricultural scientists are wrong about agriculture and conservation scientists are wrong about conservation. Endangered Species Update, 20, 53-62.

Velázquez, V. G. (1994). Los recursos hidráulicos del estado de Tabasco. Villahermosa: Universidad Juárez Autónoma del Estado de Tabasco.

White, T., Bruns, T., Lee, S. y Taylor, J. (1990). Amplification and direct sequencing of fungal ribosomal RNA genes for phylogenetics. En M. A. Innis, D. H. Gelfand, J. J. Shinsky y T. J. White (Eds.), PCR Protocols: a guide to methods and applications. (pp. 315-322). San Diego: Academic Press.

Wuczkowski, M., Druzhinina, I., Gherbawy, Y., Klug, B., Prillinger, H. y Kubicek, C. P. (2003). Species pattern and genetic diversity of Trichoderma in a mid-european, primeval floodplain-forest. Microbiology Research, 158, $1-9$

Yerdidia, I., Shoresh, M., Kerem, Z., Benhamou, N., Kapulnik, Y. y Chet, I. (2003). Concomitant induction of systemic resistance to Pseudomonas syringae pv. lachrymans in cucumber by Trichoderma asperellum (T-203) and accumulation of phytoalexins. Applied and Environmental Microbiology, 69, 7343-7353

Zhang, C., Druzhinina, I., Kubicek, C. y Xu, T. (2005). Trichoderma biodiversity in China: evidence for a North to Southern distribution of species in East Asia. FEMS Microbiology Letters, 251, 251-257. 